\title{
The Burden of Hospitalisations for Herpes Zoster Ophtalmicus in Spain (1997-2008)
}

\author{
Ruth Gil-Prieto $^{{ }^{*}}$, Alejandro Álvaro-Meca ${ }^{1}$, Alba González-Escalada Mena ${ }^{1}$, \\ José María Guillén-Ortega ${ }^{2}$, Ángel Gil-De-Miguel ${ }^{1}$ \\ ${ }^{1}$ Department of Preventive Medicine \& Public Health \& Medical Immunology \& Microbiology, Rey Juan Carlos University, Madrid, \\ Spain; ${ }^{2}$ Medical Department, Sanofi Pasteur MSD, Madrid, Spain. \\ Email: ${ }^{*}$ ruth.gil@urjc.es
}

Received May $20^{\text {th }}, 2012$; revised June 22 ${ }^{\text {nd }}, 2012$; accepted July $25^{\text {th }}, 2012$

\begin{abstract}
Purpose: This epidemiological retrospective survey aims to provide population-based estimates of the burden of hospitalisation for herpes zoster ophthalmicus in Spain during a twelve-year period (1997-2008). Methods: All hospital discharges and deaths related to herpes zoster ophthalmicus in patients older than 30 years old from 1997 to 2008 in Spain were obtained. Differences in proportions were assessed by the Chi-square test. ANOVA was used for multiple comparisons. Poisson regression was used to assess differences in the rates. Results: A total of 3029 hospital discharges in patients older than 30 years old were coded as herpes zoster ophthalmicus. Of those, 1009 were coded as primary cause of hospitalization. This corresponds to a hospitalization rate of 0.94 and 0.31 hospitalizations per 100,000 for any position and first diagnostic position, respectively. The $75 \%$ of the total discharges were in immunocompetent patients. The herpes zoster ophthalmicus hospitalization rate increased significantly during the study period. This increase was also observed for immunocompetent patients. A total of 127 and 21 deaths occurred in patients $\geq 30$ year-old hospitalized with herpes zoster ophthalmicus in any diagnostic position and principal diagnostic code, respectively during the 12-year study period. Of them, 70 (53.4\%) were in immunocompetent patients, and, of those 11 were in patients with $\mathrm{HZO}$ in the first diagnosis position. The hospitalization rate and case-fatality rate increase significantly with age from 50 years old onwards. Conclusion: HZO, a vaccine preventable disease, still causes hospitalization and death in adults in Spain.
\end{abstract}

Keywords: Epidemiology; Herpes Zoster Ophthalmicus; Hospitalisations; Spain; Varicella Zoster Virus

\section{Introduction}

Herpes zoster ophtalmicus (HZO) occurs when the varicella zoster virus is reactivated in the ophthalmic division of the fifth cranial nerve (trigeminal). The virus damages the eye and surrounding structures by secondary perineural and intraneural inflammation of sensory nerves [1]. Risk factors for the development of HZO are age, female gender, immunosupression, white ethnicity and exposure to infected individuals, the same as those for $\mathrm{HZ}$ in other locations [2].

Herpes zoster infection results from reactivation of varicella zoster virus which remains latent in sensory ganglia following varicella. In Europe, more than $95 \%$ of the adult population is VZV positive following varicella and therefore at risk of HZ [3] It is estimated that 25 to $30 \%$ of the population and up to $50 \%$ of those living until 85 years of age [4] will suffer from herpes zoster (HZ) at least once in their lifetime [5]. Complications of herpes

"Corresponding author. zoster occurs in $13 \%-26 \%$ of the cases [6,7]. Post-herpetic neuralgia (PHN) is the most common and debilitating complication [8,9], affecting 15 to $40 \%$ of cases. [7] the incidence and severity of herpes zoster and postherpetic neuralgia increase with age due to the decrease of cell-mediated immunity to Varicella-Zoster Virus (VZV). Complications are associated with excess of morbidity, but also are thought to be associated with an increase of the costs for the health care system.

Following the thoracic location, the cranial manifestation of herpes zoster is the second most common, including ophthalmic division of the trigeminal nerve, the incidence of which increases with age. Herpes zoster ophthalmic occurs in approximately $10 \%$ to $20 \%$ of herpes zoster cases [10]. Up to $50 \%$ of patients with ophthalmic zoster develop complications, which can lead to visual morbidity [11].

Main ocular complications in immunocompetent patients with ophthalmic zoster depend on the part of the eye affected and the phase of the infection and are as 
different as swelling, vesicular rash of the eyelids, uveitis, ocular hypertension or retinal necrosis $[12,13]$. HZO is considered an ophthalmic emergency, as sequelae can be severe, including chronic ocular inflammation, vision loss and disabling pain [1].

An effective and safe, live attenuated shingles (herpes zoster) vaccine has proved to reduce the incidence and burden of illness due to herpes zoster among people 50 years of age or older, as well as the morbidity from post-herpetic neuralgia among older adults [14]. A thorough epidemiological surveillance and a good understanding of the burden of diseases associated to VZV are crucial to asses any potential impact of a prevention strategy.

Hospital discharge databases are useful for establishing disease burden, as they provide a complete record of all hospitalisations and, in general, are not subject to the limitations of outpatient surveillance systems, such as under-diagnosis or deficiencies in reporting. Another advantage of these databases is the standardized diagnosis code lists that enable secular trend analysis of incident disease for a given population. The Spanish centralized discharge database, which includes $98 \%$ of hospitals of the National Health Care System (covering almost all the Spanish population), can give a reasonable approximation of the burden of HZO related hospitalisations. Furthermore, this database has been shown to be a reliable tool for enumerating cases of different infectious diseases that required hospitalisation [15].

There are limited recent published data on HZO hospitalizations throughout the world with which to compare our results and this is the first one to the date in Spain. This epidemiological retrospective survey aims to provide population-based estimates of the burden of hospitalisation for herpes zoster ophthalmicus in the general population and in immunocompetent patients in Spain during a twelve-year period (1997-2008).

\section{Materials and Methods}

\subsection{National Surveillance System for Hospital Data}

This retrospective observational descriptive study used the national surveillance system for hospital data (Conjunto Mínimo Básico de Datos; CMBD) maintained by the Ministry of Health. This system uses clinical codes from the Spanish version of the 9th International Classification of Diseases (ICD-9CM)) and covers an estimated $98 \%$ of the hospitalizations in public hospitals. Compulsory health insurance covers an estimated $99.5 \%$ of the Spanish population, but even persons not covered by health insurance can be treated in hospitals of the Health Care System [16-18].

We obtained all hospital discharges related to HZO in any listed diagnosis position during a 12 -year period (January 1, 1997 through December 31, 2008). Specific data were gathered on age, sex, region, average length of hospitalisation, diagnosis position, outcome and immunocompetent status. Immunocompetent patient was defined as a patient without HIV, disorders involving the immune mechanism, radiotherapy, chemotherapy, autoimmune disease or neoplasm.

For complications related to HZO the following codes were considered: HZ-related complications, PHN, infections, neurological conditions and otitis.

The conditions that influence the risk for hospitalizetion were: Diabetes, COPD, asthma, cardiac chronic disease and chronic renal disease.

All ICD-CM codes are listed in Table 1.

No personal data referring to patients were used in this study. Secondary analysis of anonymous data, coming from blind data bases used with epidemiologic research are not subject to IRB approval. Data were treated following the guidelines of the Declaration of Helsinki.

Table 1. ICD-9-CM (international classification of diseases $\mathbf{9}^{\text {th }}$ clinical modification) codes.

\begin{tabular}{ll}
\hline Description & ICD-9-MC \\
\hline $\begin{array}{l}\text { Herpes zoster ophthalmicus } \\
\text { Herpes zoster dermatitis of }\end{array}$ & 053.2 \\
eyelid & 053.20 \\
Herpes zoster keratoconjutivitis 053.21 & \\
Herpes zoster iridocyclitis & 053.22 \\
Other & 053.29 \\
Herpes zoster complications & $053.79-053.8$ \\
PHN & $053.12-053.13$ \\
Infections & 686 \\
HZ neurological conditions & $053.0,053.1,053.10,053.11,053.19$ \\
Bell's paralyisis & 351.0 \\
Otitis & $053.71,053.79$ \\
Conditions that influence the & \\
risk of hospitalization & \\
Diabetes & $250.0-250.93,357.2,648.00-658.04$ \\
COPD & $490-492,494.0-494.1,496$ \\
Asthma & $493.0-493.92$ \\
& $393-398 ; 401.0-402.91 ; 404.0-$ \\
Cardiac chronic disease & $405.99 ; 412 ; 414,0-414.9 ; 416.0-$ \\
& $425.0-425.49 ; 426.0-426.9 ; 427.1-$ \\
& $428.32-428.40 ; 428.42-428.9 ; 429.0$ \\
\hline & $-429.4 ; 429.7-429.9$ \\
\hline & $403-403.91 ; 585 ; 588$ \\
\hline & \\
&
\end{tabular}




\subsection{Statistical Methods}

The total number of hospitalisations for HZO during the study period, annual incidence of hospital admissions (per 100,000 population), average length of stay in the hospital (ALOS), and case-fatality rate $(\%)$ were calculated. As denominator, we used data obtained from municipal registers adjusted by the percentage of hospitalizations included in the CMBD information system. It was assumed that the distribution by age of the population covered by these public hospitals was equal to those in the general population. Differences in proportions were assessed by the Chi-square test, and confidence intervals $(95 \% \mathrm{CI})$ were calculated. ANOVA was used for multiple comparisons. The post hoc Bonferroni correction was used to adjust statistical significance for multiple comparisons. Poisson regression was used to assess differences in the hospitalisation rate during the study period in all the age groups. The significance level used was $\mathrm{p}<0.05$. Statistical analyses were performed using the Statistical Package for Social Sciences (SPSS/PASW for windows, version 17.0; Chicago, IL, USA).

The cost to the health care system of these hospitalisations related to $\mathrm{HZO}$ was calculated by considering the diagnostic cost group, the total cost and the number of discharges. Diagnostic cost group was based on the Diagnosis Related Groups (DRG) for hospitalized patient depending on discharge ICD code, age, sex, and resources consumption. Each group is supposed to include similar clinically patients, has similar weight in hospital costs and can be applied to each related patient. DRGs calculations are made by $3 \mathrm{M}$ with Core Grouping System Software [19].

\section{Results}

Hospital discharges related to herpes zoster ophthalmicus during the 12-year study period were studied. A total of 3339 hospital discharges were coded as herpes zoster ophthalmicus (considering all the population). Of those, 1165 were coded as primary cause of hospitalization. This corresponds to a hospitalization rate of 0.67 (CI 95\%: $0.65-0.70)$ and 0.23 (CI 95\%: $0.22-0.25$ ) hospitalizations per 100,000 for any position and first diagnostic position, respectively.

Of the 3339 total discharges, $91 \%$ were older than 30 years old $(\mathrm{n}=3029), 74 \%$ were older than 50 years old $(\mathrm{n}=2482), 311$ discharges corresponded to 50 - 59 year old group of age, 547 to 60 - 69 and 1624 (48.6\%) were 70 years old or older (Table 2 ).

A $75 \%(n=2509)$ of the hospitalizated patients (all ages considered) were inmunocompetent. There was a great disparity of causes of hospitalization when $\mathrm{HZO}$ was not the main cause of hospitalization, with AIDS (2, $3 \%$ ), chronic obstructive bronchitis $(1.5 \%)$ as the most important ones for the global analysis and chronic obstructive bronchitis (5.2\%), herpes zoster (4.2\%) and pneumonia $(2.7 \%)$ for the immunocompetent population sub analysis.

Mean age (SD) was 62 (22) and 58 (24) years old for all patients hospitalized with herpes zoster ophthalmicus in any diagnostic position and as principal diagnostic code, respectively and $59 \%$ and $56.2 \%$ of the patients were male, respectively. When only studying immunocompetent patients, mean age was 65 (22) and 61 (25) years old and $57.1 \%$ and $53.8 \%$ of the patients were male for patients with ophthalmic herpes zoster diagnosed in any diagnostic position and in first diagnostic position, respectively.

The HZO hospitalization rate in patients older than 30 years old increased significantly $(p<0.001)$ during the study period from 0.77 and 0.26 hospitalizations per 100,000 in 1997 to 0.92 and 0.30 hospitalizations per 100,000 in 2008 , in any diagnostic position and principal diagnostic code, respectively (Figure 1).

The average length of stay in the hospital for patients older than 30 was 13 (SD: 14) and 10 (SD: 9) days in any diagnostic position and in first diagnostic position, respectively, and did not change significantly during the study period.

A $12.4 \%$ and $6.6 \%$ of cases of the hospitalizations were readmissions, defined as any admission in the following 30 days after discharge, irrespectively of the discharge code.

The average length of stay in the hospital for immunocompetent patients older than 30 was 12 (SD: 13) and 9 (SD: 8) days in any diagnostic position and in first diagnostic position, respectively, and did not change significantly during the study period. A $9.9 \%$ and $4.5 \%$ percent of cases of the immunocompetent patients hospitalizations were readmissions.

The 55.6\% $(n=1685)$ of the hospitalized patients with $\mathrm{HZO}$ for patients older than 30 presented conditions that influence the risk for hospitalization. The most frequent were: cardiac chronic disease $(40.8 \%)$, diabetes $(16.5 \%)$, COPD (16.1\%), asthma (2.9\%), and chronic renal disease $(4.5 \%)$. A $12.6 \%$ of these patients presented HZ complications. The most frequent $\mathrm{HZ}$ complications were: neurological conditions $(8.1 \%)$, meningitis $(1.6 \%)$ and infections $(1.9 \%)$.

The $63 \%(n=1440)$ of the immunocompetent hospitalized patients with $\mathrm{HZO}$ presented conditions that influence the risk for hospitalization. The most frequent were: cardiac chronic disease (46.9\%) diabetes (18.6\%), COPD (18.3\%), asthma (3.3\%), and chronic renal disease $(5.2 \%)$.

A $12.6 \%$ of these immunocompetent hospitalized patients presented HZ complications, the most frequent ones were: neurological conditions $(8.2 \%)$, meningitis $(2 \%)$ and Bell's paralysis $(1 \%)$. 


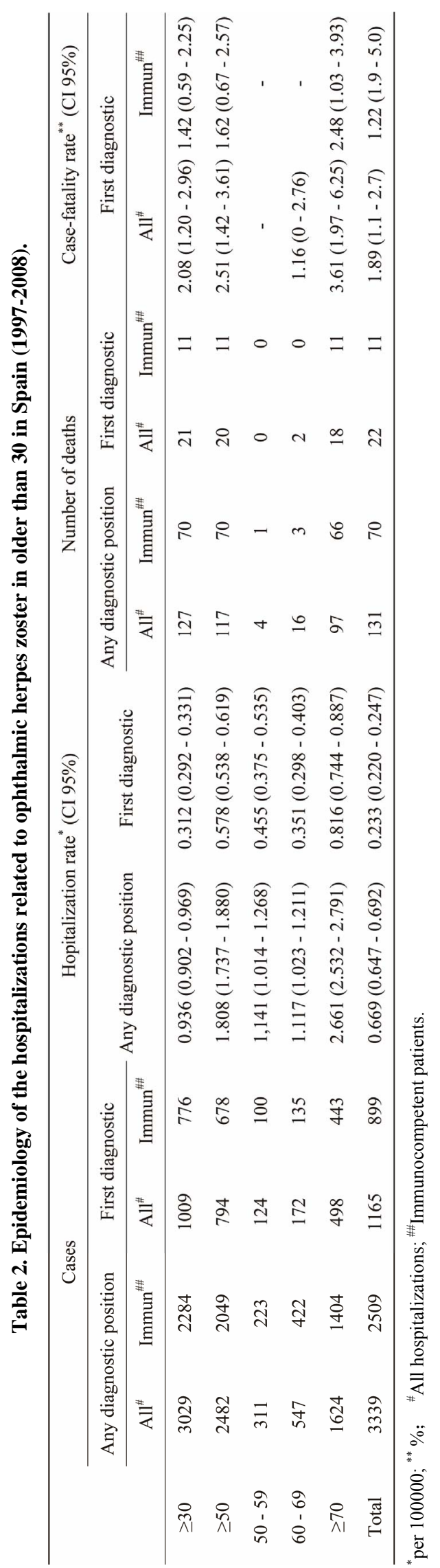


Hospitalization rates related to ophtalmic herpes zoster in older than 30 in Spain (1997-2008)

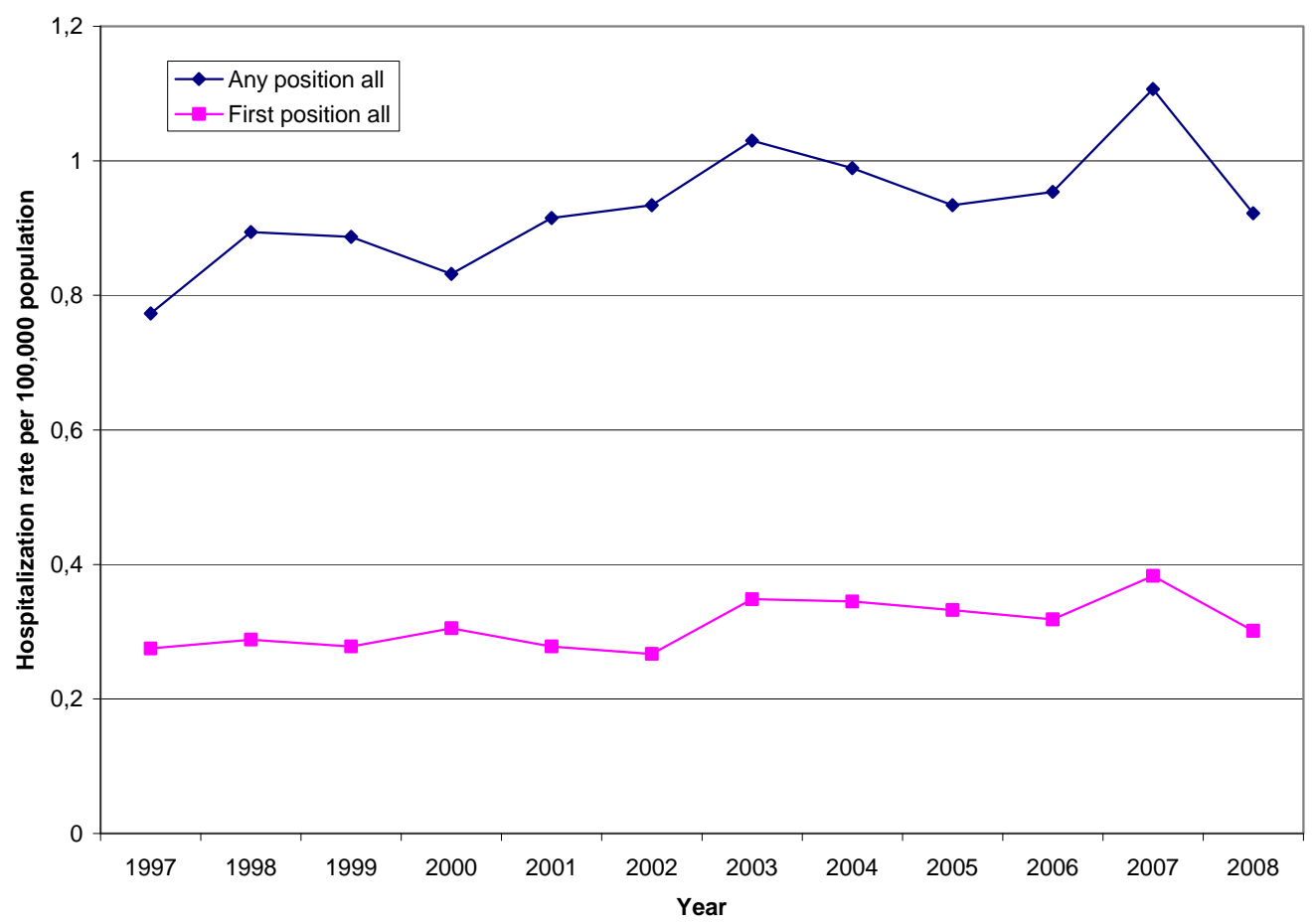

Figure 1. Hospitalization rate related to ophthalmic herpes zoster in older than 30 in Spain (1997-2008).

Among the total of 127 deaths occurring in HZO hospitalized patients older than 30 years old (Table 2), 21 were observed in patients with HZO as principal diagnostic code and 4 with $\mathrm{HZ}$ as principal diagnostic code. The case fatality rate was $2.1 \%$ (CI 95\%: 1.2 - 3.0.) for $\mathrm{HZO}$ as primary diagnosis and $2.5 \%$ (CI 95\%: $1.4-3.5$ ) if we also consider the 4 deaths in patients primarily diagnosed with $\mathrm{HZ}$.

Seventy deaths (55.1\%) occurred in immunocompetent patients, and, of those 11 were in patients with HZO in the first diagnosis position and 1 in a patient with $\mathrm{HZ}$ in the first diagnosis position. This makes a case fatality rate 1.4\% (CI 95\%: $0.6-2.2$ ) for primary diagnosis and $1.6 \%$ (CI 95\%: $0.6-2.4$ ) if we also consider the death in the patient primarily diagnosed with $\mathrm{HZ}$.

The case-fatality rate did not vary during the study period neither in patients hospitalized with ophthalmic herpes zoster in any diagnostic position or as principal diagnostic code.

Distribution of hospitalizations rates per region in Spain can be seen in Figure 2. The higher hospitalization rates were found in Ceuta, Melilla, Aragón and La Rioja with more than 1.5 hospitalizations per 100,000 population, meanwhile the lower hospitalization rate was found in The Canary Islands with 0.354 hospitalizations per 100,000.

During the 12-year period, the cost for inpatient hospital care per hospitalization was $2268 €$ for patients older than 30 years old hospitalized with HZO as the first diagnostic code. These figures are slightly lower in immunocompetent patients with $1955 €$ for principal diagnostic code. Estimated cost of these hospitalisations per year was approximately $191,000 €$ for HZO in as princepal diagnostic code, in patients older than 30 years old. In immunocompetent patients estimated cost per year was approximately $126,000 €$ for HZO as principal diagnostic code.

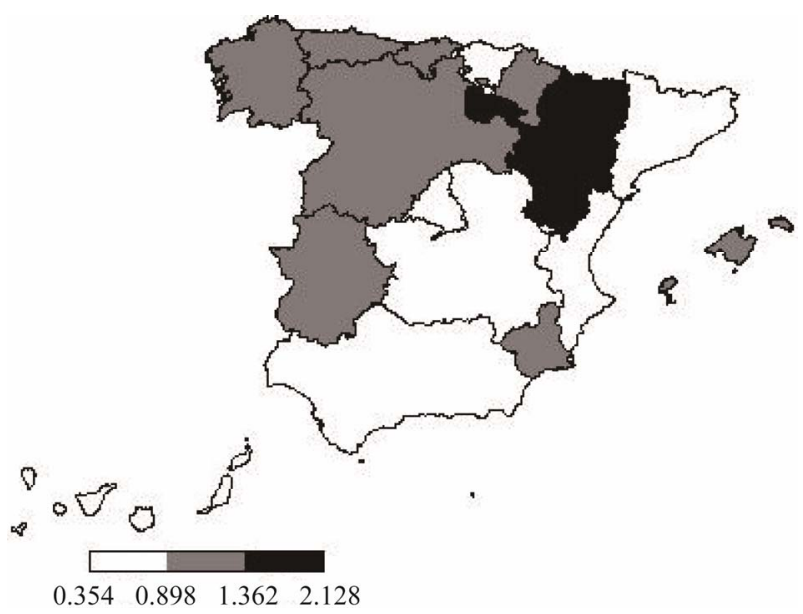

Figure 2. Hospitalization rate (per 100,000) related to ophthalmic herpes zoster in older than 30 per Authonomous Region in Spain (1997-2008). Hospitalization rates per 100,000 population; Q1. 0.3540 - 0.8985; Q2. - 0.8985 1.3620; Q3.-1.3620 - 2.1280. 


\section{Discussion}

This study reflects the burden of hospitalised HZO by reporting the population-based estimates of the burden of hospitalisations in general population in Spain from 1997 to 2008. A total of 3339 hospital discharges related to HZO occurred during the 1997-2008 period in all ages, which means an annual hospitalization rate of 0.67 per 100,000 population. More than $90 \%$ of the patients were older than 30 years old, with a sharply increased of cases with age, reaching a 2.6 per 100,000 in older than 70 .

It is considered that $\mathrm{HZO}$ represents $10 \%$ to $20 \%$ of all $\mathrm{HZ}$ cases [20]. In this study the incidence of HZO hospitalizations (considering the first diagnosis position) represented a $9 \%$ of the incidence of $\mathrm{HZ}$ hospitalizations estimated by Gil et al. for the 1998-2004 period [15].

As expected, HZ and HZO follow the same epidemicologic pattern, increasing their incidence with age accounting for more than $70 \%$ of the cases in population older than 50 years of age. These results are in line with previous published data $[21,22]$.

The gender ratio, with $59 \%$ of cases affecting male patients, is not in accordance with the fact that female gender is considered as a risk factor for HZO [2]. Gil et al. also observed a higher incidence of $\mathrm{HZ}$ hospitalizations in males than females (52\% vs $48 \%$ ) during the 1998 2004 period [15]. In most studies [23-29] the incidence of $\mathrm{HZ}$ was higher in females than in males. Differences in the use of the health care system between males and females or different immune responses to the latent viral infection could partially explain these differences [30]. However, women have usually more contact with children than men $[31,32]$. It has been proposed by different authors $[33,34]$ that contact with children reduces the risk of suffering herpes zoster in the adulthood.

This could partially explain the higher incidence of hospitalization for herpes zoster in men obtained in our study and could change in the future if varicella vaccinetion is implemented in the routine vaccine schedule at 15 months and the wild virus circulation is modified.

HZO coded in first diagnosis position represented 35\% of all the cases. This could be explained by the high percentage of hospitalized patients who presented conditions that influenced the risk for hospitalization, as these conditions could have been coded as main cause of hospitalisation instead of HZO. However, there was a great disparity of causes of hospitalization when HZO was not the main cause of hospitalization, and there was no relation with the frequencies of the different conditions that influenced the risk of hospitalization.

A $12.6 \%$ of immunocompetent hospitalized patients presented $\mathrm{HZ}$ complications, with neurological conditions, meningitis and Bell's paralysis as the most frequent ones. Both the virulence of the infection and the immune response could explain, according to Liesegang et al., [20] why some immunocompetent patients have no complications and others develop a wide range of complications.

The Autonomous City of Melilla, and the Autonomous Regions of La Rioja and Aragón presented the highest HZO hospitalization rates, while Canary Island and Andalucía presented the lowest values. This ranking is very similar to the one published by Gil et al. for HZ hospitalization in Spain [15] Canary Islands have shown the lowest varicella hospitalization rates and also the lowest $\mathrm{HZ}$ and HZO hospitalization rates [35]. This could be explained either by factors related to the patient condition (mainly age and morbidity) and the health system (clinical procedures, availability of hospital beds per 100,000 population) or by its location, in a tropical area, where varicella zoster virus circulation is probably lower.

Long-term management is required for all HZO patients, so as to avoid the potential sequelae [36]. Furthermore, the benefit of antiviral agents is shown to be limited in patients with HZO [20]. Thus, prevention takes even more importance. A $75 \%$ of the hospitalized patients in this study were immunocompetent patients, susceptible to be vaccinated with the $\mathrm{HZ}$ vaccine [37]. A vaccination strategy of the immunocompetent adult population could lead to an important reduction in the burden of hospitalizations due to HZO.

The estimated annual cost of hospitalization due to HZO in immunocompetent patients was $126,000 €$. Only direct costs were calculated. This should also be taken into account when any prevention strategy is analysed.

This study has some limitations derived from the use of CMBD. The reliability of the CMBD depends on the quality of the discharge report and the clinical history, as well as the codification process variables [38]. Quality controls have been done to assess the validity of CMBD and the codification process has improved since 2001 [39]. Nevertheless, CMBD can be considered as a useful tool for this approach.

In the present study, all ICD-9-CM codes referring to HZO have been considered. As specific data about microbiological confirmation is not available within the CMBD, information on the diagnosis is based in clinical diagnosis, which in HZO we consider to be extremely valuable. It is general practice in Spanish public hospitals to confirm VZV. CMBD does not give information on the VZV strand.

Further efforts to enhance surveillance and further studies focused in the epidemiology and the incidence of varicella and herpes zoster are needed in order to evaluate current and future preventive measures implementation.

\section{Acknowledgements}

To the Subdirección General del Instituto de Información 
Sanitaria for providing with the information in which this study is based.

\section{REFERENCES}

[1] S. Shaikh and C. N. Ta, "Evaluation and Management of Herpes Zoster Ophthalmicus," American Family Physician, Vol. 66, No. 9, 2002, pp. 1723-1730.

[2] S. L. Thomas and A. J. Hall, "What Does Epidemiology Tell Us about Risk Factors for Herpes Zoster?" The Lancet Infectious Diseases, Vol. 4, No. 1, 2004, pp. 26-33. doi:10.1016/S1473-3099(03)00857-0

[3] R. W. Johnson, G. Wasner, P. Saddier and R. Baron, "Postherpetic Neuralgia: Epidemiology, Pathophysiology and Management," Expert Review of Neurotherapeutics, Vol. 7, No. 11, 2007, pp. 1581-1595. doi:10.1586/14737175.7.11.1581

[4] K. Schmader, "Herpes Zoster in Older Adults," Clinical Infectious Diseases, Vol. 32, No. 10, 2001, pp. 1481-1486. doi: $10.1086 / 320169$

[5] M. Vázquez and E. D. Shapiro, "Varicella Vaccine and Infection with Varicella-Zoster Virus," The New England Journal of Medicine, Vol. 352, No. 5, 2005, pp. 439-440. doi:10.1056/NEJMp048320

[6] K. Galil, P. W. Choo, J. G. Donahue and R. Platt, "The Sequelae of Herpes Zoster," Archives of Internal Medicine, Vol. 157, No. 11, 1997, pp. 1209-1213. doi:10.1001/archinte.1997.00440320105010

[7] R. E. Hope-Simpson, "Postherpetic Neuralgia," The Journal of the Royal College of General Practitioners, Vol. 25, No. 157, 1975, pp. 571-575.

[8] W. J. Edmunds, M. Brisson and J. D. Rose, "The Epidemiology of Herpes Zoster and Potential Cost-Effectiveness of Vaccination in England and Wales," Vaccine, Vol. 19, No. 23-24, 2001, pp. 3076-3090. doi:10.1016/S0264-410X(01)00044-5

[9] S. Helgason, G. Petursson, S. Gudmundsson and J. A. Sigurdsson, "Prevalence of Postherpetic Neuralgia after a First Episode of Herpes Zoster: Prospective Study with Long Term Follow up," British Medical Journal, Vol. 321, No. 7264, 2000, pp. 794-796. doi:10.1136/bmj.321.7264.794

[10] A. L. Cunningham, J. Breuer, D. E. Dwyer, D. W. Gronow, R. D. Helme, J. C. Litt, M. J. Levin and C. R. Macintyre, "The Prevention and Management of Herpes Zoster," Medical Journal of Australia, Vol. 188, No. 3, 2008, pp. 171-176

[11] D. Pavan-Langston, "Ophtalmic Zoster," In: A. M. Arvin and A. A. Gershon, Eds., Varicella-Zoster Virus-Virology and Clinical Management, Cambridge University Press, Cambridge, 2000, pp. 276-298. doi:10.1017/CBO9780511601194.016

[12] W. Opstelten and M. J. Zaal, "Managing Ophthalmic Herpes Zoster in Primary Care," British Medical Journal, Vol. 331, No. 7509, 2005, pp. 147-151. doi:10.1136/bmj.331.7509.147

[13] W. P. Carter 3rd, C. A. Germann and M. R. Baumann, "Ophthalmic Diagnoses in the ED: Herpes Zoster Oph- thalmicus," The American Journal of Emergency Medicine, Vol. 26, No. 5, 2008, pp. 612-627. doi:10.1016/j.ajem.2007.08.013

[14] Schmader, et al., "Study to Evaluate the Safety and Effectiveness of Zostavax ${ }^{\text {TM }}$ in Subjects 50-59 Years of Age (V211-022)," Clinical Infectious Diseases, Vol. 54, No. 7, 2012, pp. 922-928.

http:/clinicaltrials.gov/ct2/show/results/NCT00534248?te $\mathrm{rm}=$ Zostavax\&rank=2

[15] A. Gil, R. Gil, A. Alvaro, M. S. Martín and A. González, "Burden of Herpes Zoster Requiring Hospitalization in Spain during a Seven-Year Period (1998-2004)," BMC Infectious Diseases, Vol. 9, No. 55, 2009. doi:10.1186/1471-2334-9-55

[16] Ministerio de Sanidad y Consumo, "Clasificación Internacional de Enfermedades 9 Revisión, Modificación clínica," 1996, pp. 375-376.

http://www.msc.es/estadEstudios/estadisticas/normalizaci on/clasifEnferm/instrucNorma.htm

[17] Instituto Nacional de la Salud, "Subdirección General de Coordinación Administrativa. Conjunto Mínimo Básico de Datos. Hospitales del INSALUD2001. Madrid 2002," 2010. http://www.ingesa.msc.es/

[18] C. A. Rivero, "El Conjunto Mínimo Básico de Datos en el SNS: Inicios y Desarrollo Actual," Revista Fuentes Estadísticas, Vol. 49, 2000, pp. 18-19.

http://www.ingesa.msc.es/estadEstudios/documPublica/p df/grds-2001.pdf

[19] J. Schreyögg, T. Stargardt, O. Tiemann and R. Busse, "Methods to Determine Reimbursement Rates for Diagnosis Related Groups (DRG): A Comparison of Nine European Countries," Health Care Management Science, Vol. 9, No. 3, 2006, pp. 215-223. doi:10.1007/s10729-006-9040-1

[20] T. J. Liesegang, "Herpes Zoster Ophthalmicus Natural History, Risk Factors, Clinical Presentation, and Morbidity," Ophthalmology, Vol. 115, Suppl. 2, 2008, pp. S3S12. doi:10.1016/j.ophtha.2007.10.009

[21] P. LaRussa, "The Success of Varicella Vaccine," Pediatric Annals, Vol. 31, No. 11, 2002, pp. 710-715.

[22] J. C. Bramley and I. G. Jones, "Epidemiology of Chickenpox in Scotland: 1981 to 1998," Communicable Disease and Public Health, Vol. 3, No. 4, 2000, pp. 282-287.

[23] B. P. Yawn, P. Saddier, P. C. Wollan, J. L. St. Sauver, M. J. Kurland and L. Sy, "A Population-Based Study of the Incidence and Complication Rates of Herpes Zoster before Zoster Vaccine Introduction," Mayo Clinic Proceedings, Vol. 82, No. 11, 2007, pp. 1341-1349. doi: $10.4065 / 82.11 .1341$

[24] C. M. García, J. Castilla, Y. Montes, J. Morán, A. Salaberri, F. Elía, Y. Floristán, I. Rodrigo, F. Irisarri, M. Arriazu, A. Zabala and A. Barricarte, "Incidencia de la Varicela y el Herpes Zoster Antes de la Introducción de la Vacunación Sistemática Infantil en Navarra, 2005-2006," Anales del Sistema Sanitario de Navarra, Vol. 31, 2008, pp. 71-80.

[25] N. Pérez-Farinós, M. Ordobás, C. García-Frenández, L. García-Comas, S. Cañellas, I. Rodero, A. Gutiérrez-Rodríguez, J. García-Gutiérrez and R. Ramírez, "Varicella 
and Herpes Zoster in Madrid, Based on the Sentinel General Practitioner Network: 1997-2004," BMC Infectious Diseases, Vol. 7, No. 59, 2007. doi:10.1186/1471-2334-7-59

[26] R. Insinga, R. F. Itzler, J. M. Pellissier, P. Saddier and A. A. Nikas, "The Incidence of Herpes Zoster in a United States Administrative Database," Journal of General Internal Medicine, Vol. 20, No. 8, 2005, pp. 748-753. doi:10.1111/j.1525-1497.2005.0150.x

[27] A. Gautier, J. Breuer, D. Carrington, M. Martin and V. Rèmy, "Epidemiology and Cost of Herpes Zoster and Post-Herpetic Neuralgia in the United Kingdom," Epidemiology \& Infection, Vol. 137, No. 1, 2009, pp. 38-47. doi:10.1017/S0950268808000678

[28] Ch. Chidiac, J. Bruxelle, J. P. Daures, T. Hoang-Xuan, P. Morel, A. Leplège, A. El Hasnaoui and C. de Labareyre, "Characteristics of Patients with Herpes Zoster on Presentation to Practitioners in France," Clinical Infectious Diseases, Vol. 33, No. 1, 2001, pp. 62-69. doi:10.1086/320884

[29] W. Opstelten, G. A. Van Essen, F. Schellevis, T. Verheij and K. Moons, "Gender as Independent Risk Factor for Herpes Zoster: A Population Based Study," Annals of Epidemiology, Vol. 16, No. 9, 2006, pp. 692-695. doi:10.1016/j.annepidem.2005.12.002

[30] D. M. Fleming, K. W. Cross, W. A. Cobb and R. S. Chapmna, "Gender Difference in the Incidence of Shingles," Epidemiology \& Infection, Vol. 132, No. 1, 2004, pp. 1-5. doi:10.1017/S0950268803001523

[31] B. Law, C. Fitzsimon, L. Ford-Jones, N. MacDonald, P. Dèry and W. Vaudry, "Cost of Chickenpox in Canada: Part I. Cost of Uncomplicated Cases," Pediatrics, Vol. 104, No. 1, 1999, pp. 1-6. doi:10.1542/peds.104.1.1
[32] E. Somekh, I. Dalal, T. Shohat, G. M. Ginsberg and O. Romano, "The Burden of Uncomplicated Cases of Chickenpox in Israel," Journal of Infection, Vol. 45, No. 4, 2002, pp. 233-236. doi:10.1053/jinf.2002.1039

[33] M. Brisson, W. J. Edmunds, N. J. Gay, B. Law and G. De Serres, "Modelling the Impact of Immunization on the Epidemiology of Varicella Zoster Virus," Epidemiology and Infection, Vol. 125, No. 3, 2002, pp. 651-669. doi:10.1017/S0950268800004714

[34] M. Salleras, et al., "Contacts with Children and Young People and Adult Risk of Suffering Herpes Zoster," Vaccine, Vol. 29, No. 44, 2011, pp. 7602-7605. doi:10.1016/j.vaccine.2011.08.023

[35] J. M. Guillen, R. Gil-Prieto, A. Alvaro and A. Gil, "Burden of Adult Varicella Hospitalizations in Spain (20012007)," Human Vaccines and Immunotherapeutics, Vol. 6, No. 8, 2010, pp. 659-663. doi:10.4161/hv.6.8.12014

[36] A. S. Gurwood, J. Savochka and B. J. Sirgany, "Herpes Zoster Ophthalmicus," Optometry, Vol. 73, No. 5, 2002, pp. 295-230.

[37] Zostavax SmPC, 2011 http://www.ema.europa.eu/docs/en_GB/document_library /EPAR - Product Information/human/000674/WC̄50005 3462.pdf

[38] S. Peiro and J. Librero, "Evaluación de la Calidad a Partir del Conjunto MÍnimo de Datos Básicos al Alta Hospitalaria," Revista de Neurología, Vol. 29, 1999, pp. 651661.

[39] Ministerio de Sanidad y Consumo, "Análisis y Desarrollo de los GDR en el Sistema Nacional de Salud," 2010. www.msc.es/estadEstudios/estadisticas/docs/analisis.pdf 